\title{
The role of deposition temperature and catalyst thickness in graphene domains on $\mathrm{Cu}$
}

\author{
Azadeh Jafari $^{1} \cdot$ Mahmood Ghoranneviss $^{1} \cdot$ Mojtaba Gholami $^{2}$ N. Mostahsan ${ }^{1}$
}

Received: 21 January 2015/Accepted: 20 July 2015/Published online: 16 September 2015

(c) The Author(s) 2015. This article is published with open access at Springerlink.com

\begin{abstract}
Few layered graphene is synthesized on $\mathrm{Cu}$ foil by thermal chemical vapor deposition. We have investigated the effect of temperature and catalyst's thickness on graphene domain length and number. The synthesized graphene was characterized using Raman spectroscopy and scanning electron microscopy. Raman spectroscopy results show that D-peak intensity increases with an increasing temperature which revealing that some defects have been generated during synthesis on $\mathrm{Cu}$ surface synthesis at higher temperature. It also has been observed that increasing in temperatures result in more intense 2D peaks. Although for further rise in temperature, although the number of graphene domain increases and the graphene domain length reduces. Our results provide important guidance toward the synthesis of high quality graphene films.
\end{abstract}

Keywords Graphene $\cdot$ TCVD $\cdot$ Raman $\cdot$ SEM

\section{Introduction}

Despite the advances in graphene research, obtaining a controlled method on film size which can produce larger crystalline graphene domains is still unavailable. This

Mojtaba Gholami

m.gholami.darvan@gmail.com

Azadeh Jafari

jafari_manesh@yahoo.com

Mahmood Ghoranneviss

Ghoraneviss@pprc.srbiau.ac.ir

1 Plasma Physics Research Center, Science and Research Branch, Islamic Azad University, Tehran, Iran

2 Department of Physics, Payam Noor University, Tehran, Iran clarifies that researches on graphene growth still needs to be improved. Investigation of structural evolution and growth mechanism can provide guidance to produce desired graphene. The involved parameters in graphene growth have been explored in many studies. High quality single layer and multilayer graphene were synthesized by tuning the growth conditions such as using different gaseous, liquid or solid carbon sources [1], different dilution gases [1,2] with different flow rates [3], different temperature, process pressure [2], cooling rates [4] as well as catalysts [3], catalyst's thickness, crystallographic orientation [4] and purity states $[4,5]$. Thermal chemical vapor deposition (TCVD) of graphene on copper using a gaseous mixture as hydrocarbon source appears to be the most appropriate choice to obtain large area monolayer graphene which can be easily transferred to different substrates in an economical way [6-15]. However, there are some inevitable parameters which are widely degrading the as grown graphene films such as hydrogen concentration, process pressure, hydrocarbon source, catalyst thickness and purity state [14-16].

The aim of this study is to investigate the growth of graphene by TCVD and to understand how the temperature and catalyst's thickness affect the structure and the quality of resulted graphene domains. Graphene domains were produced at different temperatures from 800 to $1000{ }^{\circ} \mathrm{C}$ under a $\left(\mathrm{C}_{2} \mathrm{H}_{2}+\mathrm{H}_{2}+\mathrm{Ar}=30 / 20 / 900\right)$ flowing gas mixture. Our experiments resulted in growth of few layers graphene domains.

\section{Experimental methods}

The graphene films were synthesized by TCVD on both $\sim 50 \mu \mathrm{m}$ copper foil with (001) crystallographic orientation and $\sim 5 \mathrm{~mm}$ copper plate (001) both with $\sim 99.5 \%$ 
purity using methane as the source of carbon. The experimental instrument consists of a quartz tube, a CVD chamber, heating system and channel gas flowing systems. The substrates were cut $1 \times 1 \mathrm{~cm}^{2}$. They have been etched following a common protocol of acetone, alcohol and deionized water. Then they were loaded in TCVD tube. The experiments have been realized under ambient pressure. In order to smooth the substrate surface and to reduce native copper oxide and other impurities on the surface, the samples have been annealed for 20 min under Argon prior to growth process in order to smooth the substrate surface and to reduce native copper oxide and other impurities on the surface. Argon flow was set to be $900 \mathrm{sccm}$ and was kept unchanged during the whole experiment. The annealing temperatures each time were set to be the same as work temperature. Then the growth process started by introducing methane $(\sim 27.5 \mathrm{sccm})$ together with hydrogen $(\sim 20 \mathrm{sccm})$ for $10 \mathrm{~min}$. The TCVD treatment were performed at different temperatures 700, 800, 900, 950 and $1000{ }^{\circ} \mathrm{C}$. Once the TCVD growth had finished, the quartz tube was cooled down to room temperature. The graphene quality was characterized quantitatively using Raman spectroscopy and scanning electron microscopy (SEM). The Raman measurements were carried out with SENTERRA (2009) system using a confocal depth profiling with true focus and resolution of $2 \mu \mathrm{m}$. The excitation source of Raman spectroscopy was a $785 \mathrm{~nm}$ laser with a laser power of $10 \mathrm{~mW}$. The SEM studies of graphene on $\mathrm{Cu}$ substrates were performed using HITACHI S 4160 system.

\section{Result and discussion}

Experiments have been realized at 700, 800, 900, 950 and $1000{ }^{\circ} \mathrm{C}$. For growth temperature below $800{ }^{\circ} \mathrm{C}$, no graphene has been observed. In order To investigate the effect of $\mathrm{Cu}$ substrate thickness, different $\mathrm{Cu}$ substrates $\mathrm{Cu}$ foils and $2 \mathrm{Cu}$ plates) have been explored at each temperature. The growth time of $10 \mathrm{~min}$ was identical for all samples. From the SEM image (Fig. 1a, b), we one can see the appearance of graphene domains after $10 \mathrm{~min}$ of growth.

Darker patches in Fig. 1a, b corresponds to graphene domains and the bright regions are $\mathrm{Cu}$ substrate. As it can also be seen, also some additional brighter dots are present which are mostly distributed on $\mathrm{Cu}$ substrate (Fig. 1b). This has been partially observed on $\mathrm{Cu}$ plate as well (Fig. 1c).These brighter dots are preferred to stay at the step edges in region where no graphene-coating occurred. These scattered dots are would be more intensively present with further increasing of the temperature (Figs. 3c, 5c, $6 b)$. The presence of these dots reveals that the grown film is probably graphene/ $\mathrm{Cu}_{\mathrm{x}} \mathrm{O}$ film [4]. It has been reported that the quantity of $\mathrm{Cu}_{\mathrm{x}} \mathrm{O}$ nanodots and the quality of grown graphene is highly dependent on growth pressure. At relatively low pressure $(\sim 80 \mathrm{~Pa})$, a large quantity of $\mathrm{Cu}_{\mathrm{x}} \mathrm{O}$ nanodots appears on graphene domain boundaries. At relatively higher pressure which is the case in this work, the graphene grows much faster and saturates the copper surface quickly which leading to a low density of $\mathrm{Cu}_{\mathrm{x}} \mathrm{O}$ as it can be seen in Figs. 1, 3, 5 and 6.

Moreover, the methane-to-hydrogen ratio $(r)$ in this work was kept to be at 1.5 . For such a low methane concentration, nanodots are reported to be more prevalent which can suppress the growth of continuous graphene coverage [4]. For further rise in temperature up to 900, 950 and $1000{ }^{\circ} \mathrm{C}$, more areas with graphene domains can be observed (Figs. 3, 4, 5). Although SEM images show the well-defined graphene domains on $\mathrm{Cu}$ plates at $900{ }^{\circ} \mathrm{C}$ (Fig. 3d), however this is not the case for sample deposited at higher temperatures. For deposition temperature more than $900{ }^{\circ} \mathrm{C}$, the samples are fully covered by small graphene domains.

Graphene domain length $L_{a}$ can be estimates using the relation below $[16,17]$ :

$I_{D} / I_{G}=C(\lambda) / L_{a}$

where $C(\lambda)=2.4 \times 10^{-4}$ and $\lambda$ is the wavelength of Raman laser, $I_{D}$ and $I_{G}$ are the intensities of the D-band and G-band respectively.

The calculated graphene domain length is plotted in Fig. 2. The length of graphene domain for $800{ }^{\circ} \mathrm{C}$ deposited graphene on $\mathrm{Cu}$ foil is about $35 \mathrm{~nm}$. Further increasing in temperature up to $900{ }^{\circ} \mathrm{C}$ gives larger graphene domain about $65 \mathrm{~nm}$. However, 950 and $1000{ }^{\circ} \mathrm{C}$ deposited samples have smaller graphene domains. Figure 2 also shows that at each given temperature, graphene domains on $\mathrm{Cu}$ plate are larger than graphene domains on $\mathrm{Cu}$ foil. At $800{ }^{\circ} \mathrm{C}$, the graphene domain length on $\mathrm{Cu}$ plate is around $55 \mathrm{~nm}$ while it is around $35 \mathrm{~nm}$ for $\mathrm{Cu}$ foil. These values increase up to $70 \mathrm{~nm}$ for $\mathrm{Cu}$ plate and $65 \mathrm{~nm}$ for $\mathrm{Cu}$ foil deposited at $900{ }^{\circ} \mathrm{C}$. However, the calculated length of graphene domains for samples deposited at $950{ }^{\circ} \mathrm{C}$ decrease to $\sim 40 \mathrm{~nm}$ for $\mathrm{Cu}$ foil and to $\sim 35 \mathrm{~nm}$ for $\mathrm{Cu}$ plate.

Although at relatively high temperatures, the graphene domains length is to be reduced, however their number increases. SEM images show large number of graphene domains for deposition temperatures of 950 and $1000{ }^{\circ} \mathrm{C}$. They also reveal that these graphene domains have irregular shape which also has been reported elsewhere (Figs. 5 and 6) $[12,18]$. At any given temperature, graphene is known to preferentially nucleate on surface irregularities and impurities, such as foil processing grooves which lead to small sizes of graphene domains [14-16]. SEM images of samples deposited at 950 and $1000{ }^{\circ} \mathrm{C}$ (Figs. 5 and 6) 

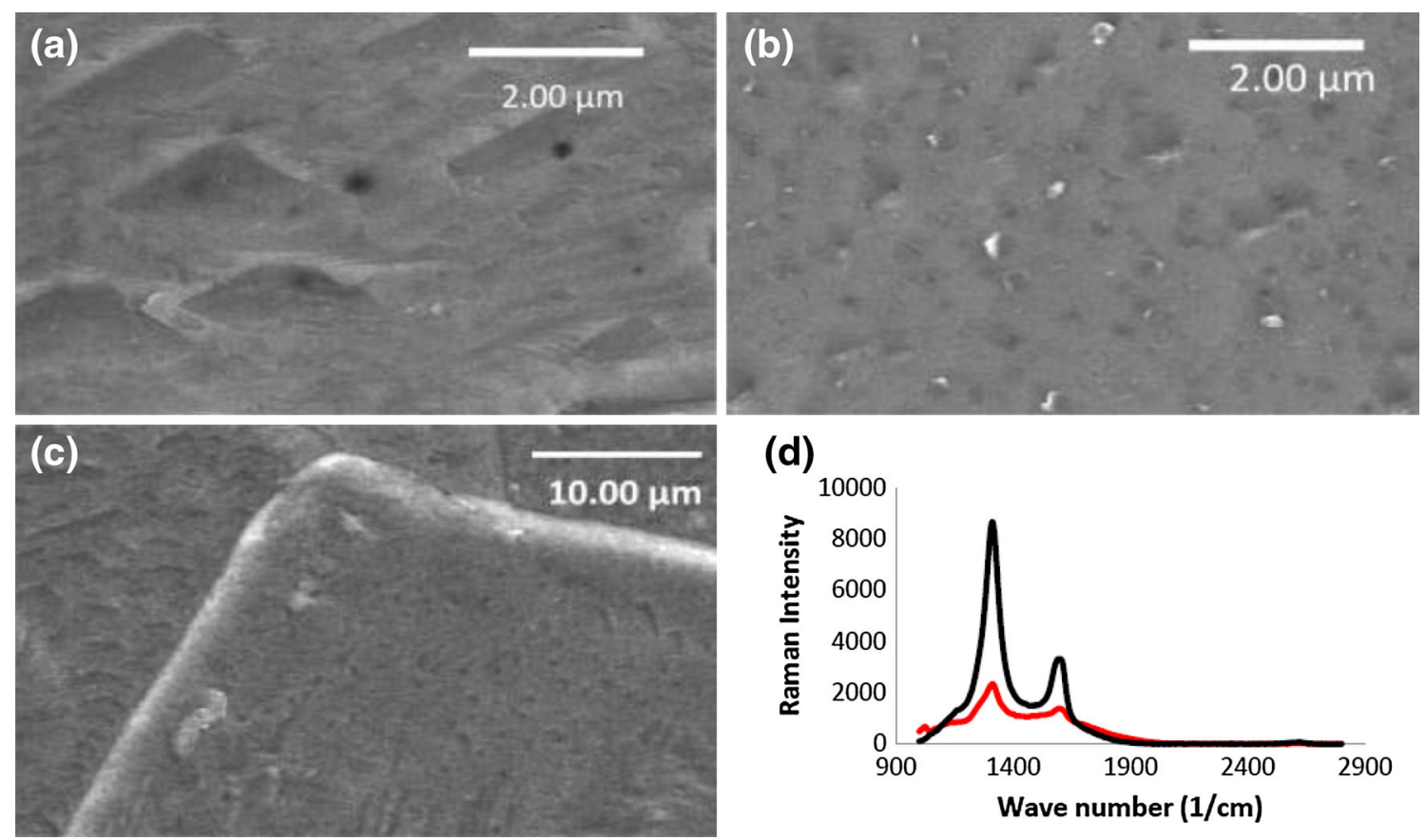

Fig. 1 Scanning electron microscope images of graphene domains on $\mathbf{a}$ and $\mathbf{b} \mathrm{Cu}$ foil at different scales, $\mathbf{c} \mathrm{Cu}$ plate at $800{ }^{\circ} \mathrm{C}$. d Corresponding Raman spectra of the same samples, black and red curves describe graphene domains on $\mathrm{Cu}$ foil and $\mathrm{Cu}$ plate respectively

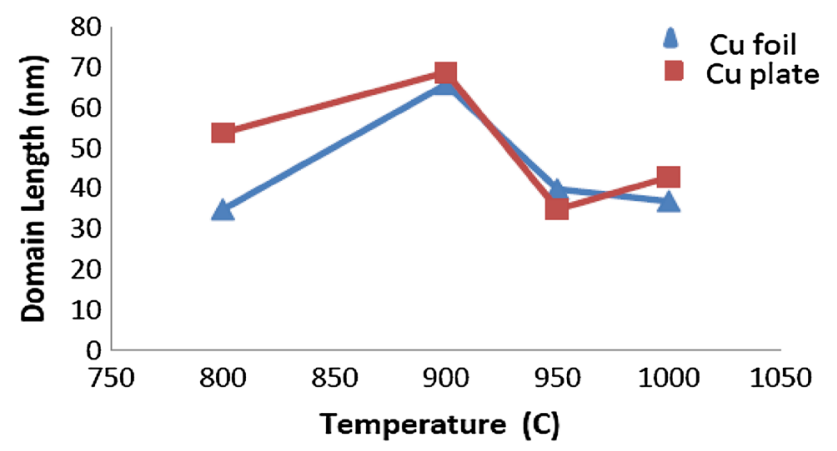

Fig. 2 Calculated graphene domain length

show numbers of carbon islands nucleated around impurity particles on the $\mathrm{Cu}$ surface.

A typical Raman spectroscopy of sample deposited at $800{ }^{\circ} \mathrm{C}$ is presented in Fig. 1d which identifies few layer graphene. It shows a D-peak at $\sim 1312 \mathrm{~cm}^{-1}$ and a G-peak at $\sim 1595 \mathrm{~cm}^{-1}$ (for both $\mathrm{Cu}$ plate and $\mathrm{Cu}$ foil grown graphene). Also the D-band intensity in both cases is much stronger than that of G-band with $I_{\mathrm{D}} / I_{\mathrm{G}}$ of about 2.6 for $\mathrm{Cu}$ foil and 1.7 for $\mathrm{Cu}$ plates grown graphene. The full width at half-maximum (FWHM) of the $\mathrm{G}$-band for $\mathrm{Cu}$ foil grown graphene is about $\sim 100 \mathrm{~cm}^{-1}$. However, the defect-induced D-band intensity is strong with FWHM of about $\sim 80 \mathrm{~cm}^{-1}$. It has been reported that as the number of graphene layers increase, the D-peak should be are normally encountered [19]. In general, for all samples Raman spectra show that the D peak intensity increases with an increasing in temperature. It can be concluded that some defects have been generated during synthesis on $\mathrm{Cu}$ surface at higher temperature (Figs. 1d, 3b, 5d, 6d).

The Raman spectra of the samples deposited at 900, 950 and $1000{ }^{\circ} \mathrm{C}$ (Figs. 3b, 5d, 6d) illustrate similar growth for both $\mathrm{Cu}$ catalysts except for 2D-band. Figure 4 shows Raman spectra near 2D peaks region for samples deposited at 900,950 and $1000{ }^{\circ} \mathrm{C}$. As it can be seen, increasing in temperature results in more significant 2D-peaks intensity. The intensity of 2D-peak varies from $\sim 80$ (au) for sample deposited at $900{ }^{\circ} \mathrm{C}$ to $\sim 800$ (au) for sample deposited at $1000{ }^{\circ} \mathrm{C}$. Although increasing the temperature results in smaller graphene domains, the intensity of 2D-peak as well as the density of graphene domains increases. One can conclude that higher temperature may produce higher density of smaller graphene domains which may laterally join together and fully cover the catalyst surface.

For graphene domains on $\mathrm{Cu}$ foils for example, 2Dpeaks are presented at $2605.5 \mathrm{~cm}^{-1}$ with FWHM of $\sim 90 \mathrm{~cm}^{-1}, 2615.5 \mathrm{~cm}^{-1}$ with FWHM of $\sim 150 \mathrm{~cm}^{-1}$, $2609.5 \mathrm{~cm}^{-1}$ with FWHM of $\sim 200 \mathrm{~cm}^{-1}$ for 900,950 and $1000{ }^{\circ} \mathrm{C}$ respectively (Fig. 4). According to Nasir K. Momen et al., the 2D band of single layer graphene occurs at about $\sim 2660 \mathrm{~cm}^{-1}$ and a 2D peak around this wave number is typically associated with few layer graphene [19] which has also been reported elsewhere [15, 17].

Since the shape of the 2D band reflects the electronic band structure of the graphene lattice according to Refs. $[20,21]$, we can infer that the electronic band structure of 

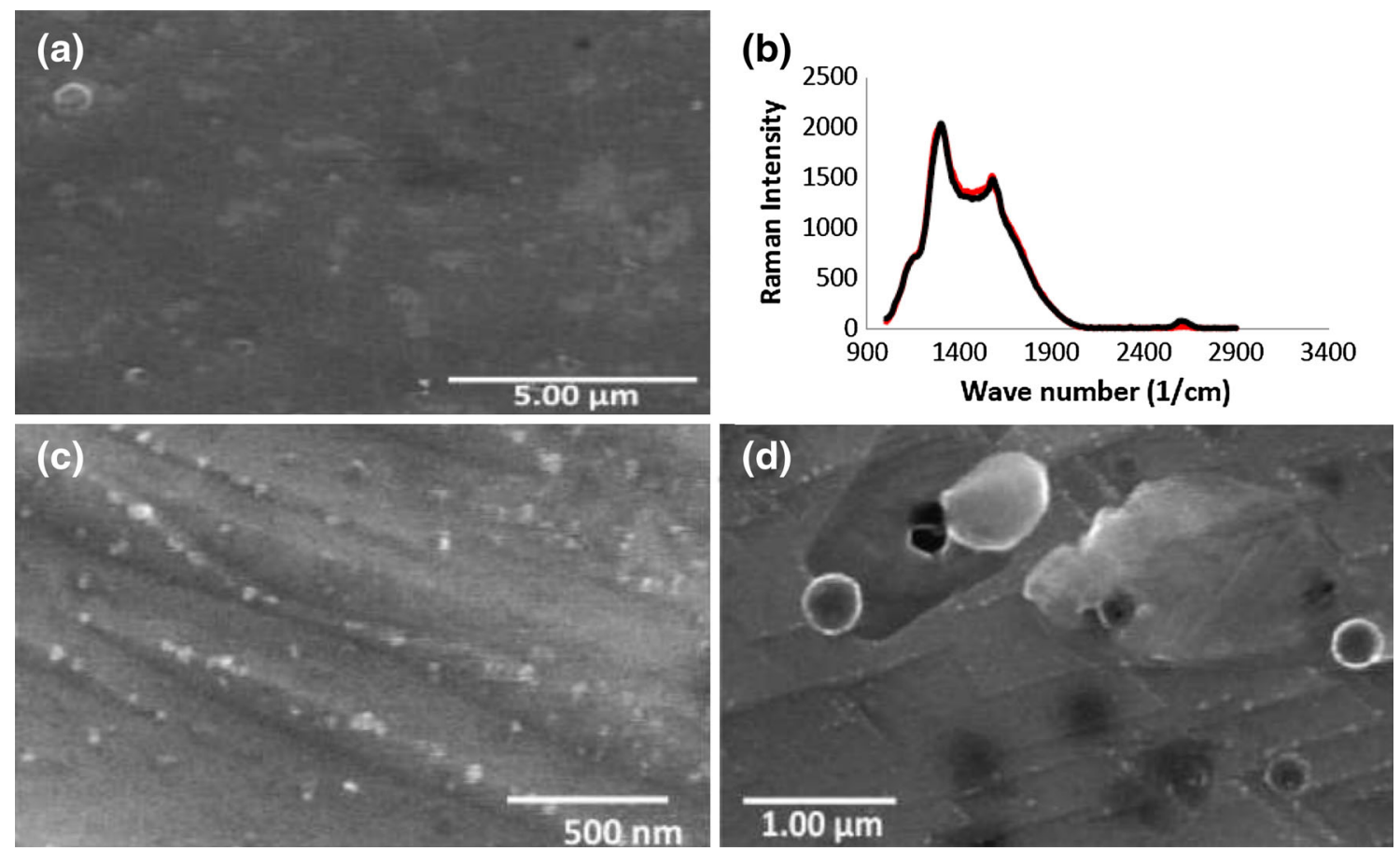

Fig. 3 Scanning electron microscope images of graphene domains on a Cu foil, $\mathbf{c}$ and $\mathbf{d ~ C u}$ plate at $900{ }^{\circ} \mathrm{C}$. b Corresponding Raman spectra of the same samples, black and red curves describe graphene domains on $\mathrm{Cu}$ foil and $\mathrm{Cu}$ plate respectively
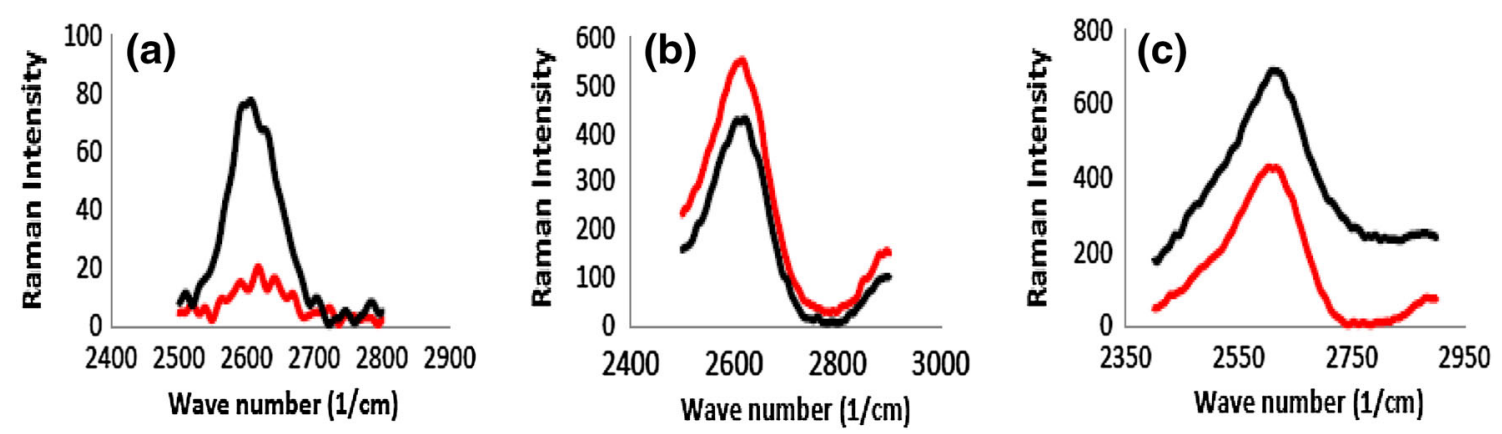

Fig. 4 Raman spectra of a samples deposited at $900{ }^{\circ} \mathrm{C}$ and b samples deposited at $950{ }^{\circ} \mathrm{C}$ and $\mathbf{c}$ samples deposited at $1000{ }^{\circ} \mathrm{C}$. Black and red curves correspond to graphene grown on $\mathrm{Cu}$ foil and $\mathrm{Cu}$ plate respectively

few layers of graphene is very similar to graphite. There is also an overall shift of the 2D band with increasing number of layers. Therefore, by combining the intensity images of the $\mathrm{G}$ and the $2 \mathrm{D}$ bands, one can reliably estimate the number of graphene layers, whiles It is known that the distance between graphene layers is about $0.335 \mathrm{~nm}$ in graphite lattice.

\section{Conclusion}

We have investigated the effect of temperature and catalyst's thickness on graphene domain length and number. For deposition temperature below $800{ }^{\circ} \mathrm{C}$, no graphene formation has been observed. SEM images show the appearance of graphene domains after $10 \mathrm{~min}$ of growth for temperatures above $800{ }^{\circ} \mathrm{C}$. The presence of some bright nanodots in SEM images reveal that the grown film is probably graphene/ $\mathrm{Cu}_{\mathrm{x}} \mathrm{O}$ film. From 800 to $900{ }^{\circ} \mathrm{C}$, graphene domain length increases. For further rise in temperature, the number of graphene domain increases the graphene domain length reduces. Moreover, at each given temperature, graphene domains on $\mathrm{Cu}$ plates are larger than graphene domains on $\mathrm{Cu}$ foil. Raman Spectroscopy results show that D-peak intensity increases with an increasing the temperature which reveals that some defects have been generated during synthesis on $\mathrm{Cu}$ surface at higher temperatures. It also has been observed that increasing in 

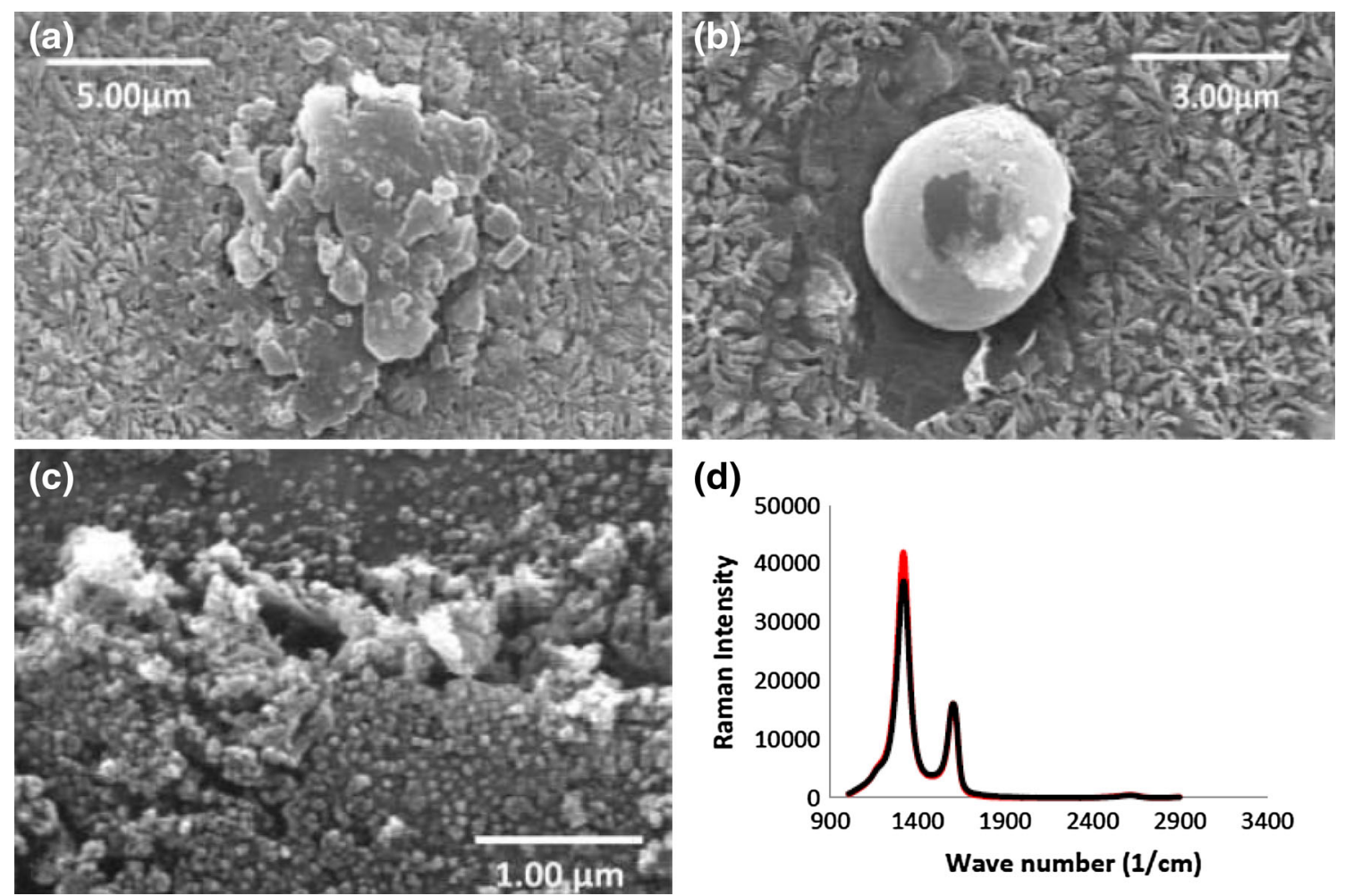

Fig. 5 Scanning electron microscope images of graphene domains on a and $\mathbf{b} \mathrm{Cu}$ foil, $\mathbf{c} \mathrm{Cu}$ plate at $950{ }^{\circ} \mathrm{C}$. $\mathbf{d}$ Corresponding Raman spectra of the same samples, black and red curves describe graphene domains on $\mathrm{Cu}$ foil and $\mathrm{Cu}$ plate respectively
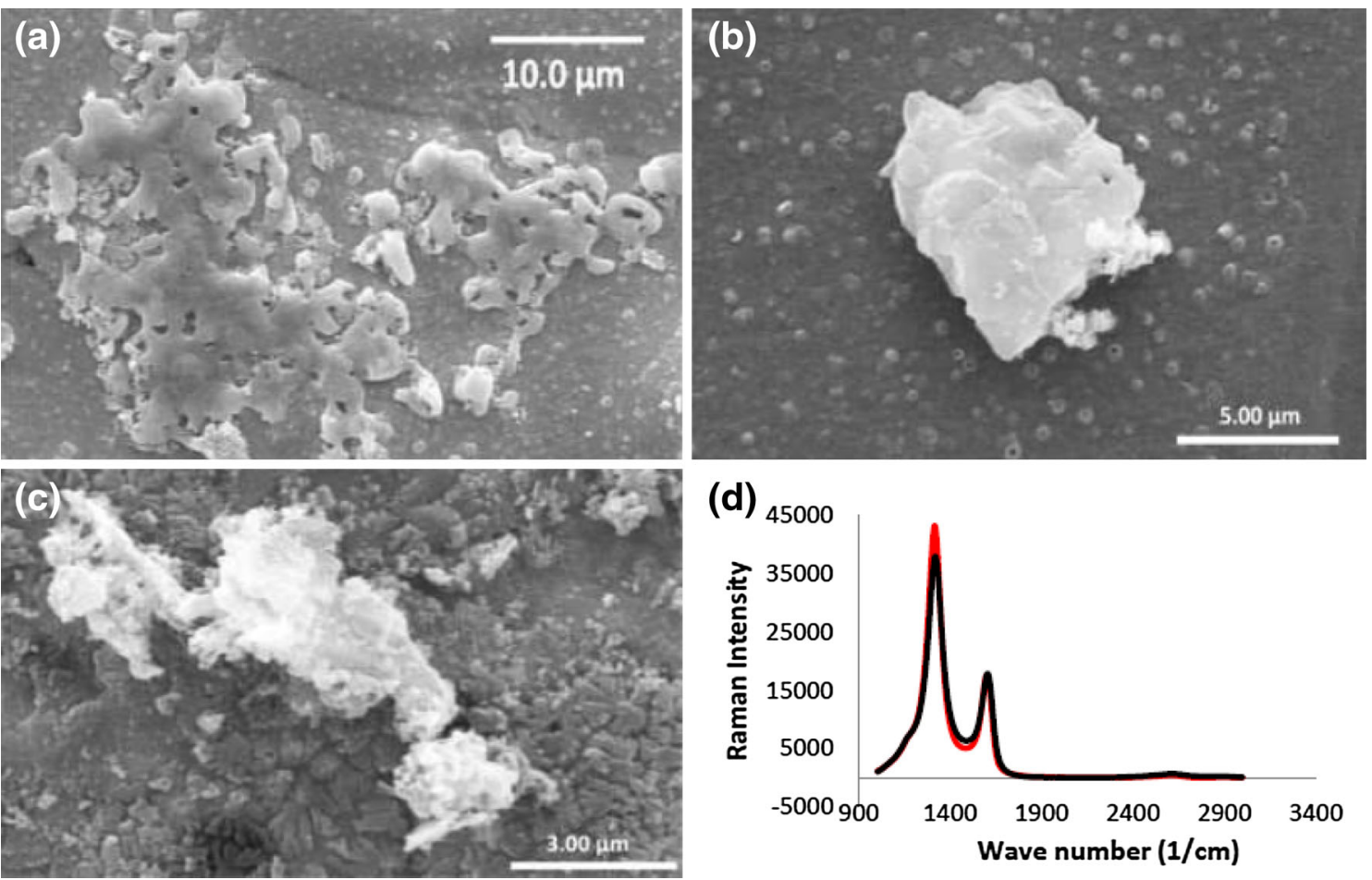

Fig. 6 Scanning electron microscope images of graphene domains on $\mathbf{a}$ and $\mathbf{b} \mathrm{Cu}$ foil, $\mathbf{c} \mathrm{Cu}$ plate at $1000{ }^{\circ} \mathrm{C}$. $\mathbf{d}$ Corresponding Raman spectra of the same samples, black and red curves describe graphene domains on $\mathrm{Cu}$ foil and $\mathrm{Cu}$ plate respectively 
temperatures results in more intense $2 \mathrm{D}$ peaks. This latter indicating that further increasing in temperature may result in fully coverage of catalyst surface by graphene.

Open Access This article is distributed under the terms of the Creative Commons Attribution 4.0 International License (http://crea tivecommons.org/licenses/by/4.0/), which permits unrestricted use, distribution, and reproduction in any medium, provided you give appropriate credit to the original author(s) and the source, provide a link to the Creative Commons license, and indicate if changes were made.

\section{References}

1. Kraus, J., Bocklein, S., Reichelt, R., Gunther, S., Santos, B., Mentes, T.O., Locatelli, A.: Towards the perfect graphene membrane-improvement and limits during formation of high quality graphene grown on Cu-foils. Carbon 64, 377-390 (2013)

2. Zhang, J., Hu, P., Wang, X., Wang, Z.: Structural evolution and growth mechanism of graphene domains on copper foil by ambient pressure chemical vapor deposition. Chem. Phys. Lett 536, 123-128 (2012)

3. Kumar, A., Voevodin, A.A., Zemlyanov, D., Zakharov, D.N., Fisher, T.S.: Rapid synthesis of few layer graphene over $\mathrm{Cu}$ foil. Carbon 50, 1546-1553 (2012)

4. Sarno, M., Cirillo, C., Piscitelli, R., Ciambelli, P.: A study of the key parameters, including the crucial role of $\mathrm{H} 2$ for uniform graphene growth on Ni foil. J. Mol. Catal. A Chem 366, 303-314 (2013)

5. Ge, W., Lu, B., Li, W., Lu, J., Ye, Z.: Synthesis of graphene together with undesired $\mathrm{Cu}_{\mathrm{x}} \mathrm{O}$ nanodots on copper foils by lowpresure chemical vapor deposition. Vacuum 97, 9-14 (2013)

6. Xiao, Y., Kim, H., Mattevi, C., Chhowalla, M., Maher, R.C., Cohen, L.F.: Influence of $\mathrm{Cu}$ substrate topography on the growth morphology of chemical vapour deposited graphene. Carbon $\mathbf{6 5}$, 7-12 (2013)

7. Li, Y., Li, M., Gu, T., Bai, F., Yu, Y., Trevor, M., Yu, Y.: An important atomic process in the CVD growth of graphene: sinking and up-floating of carbon atom on copper surface. Appl. Surf. Sci 284, 207-213 (2013)

8. Hu, B., Ago, H., Ito, Y., Kawahara, K., Tsuji, M., Magome, E., Sumitani, K., Mizuta, N., Ikeda, K., Mizuno, S.: Epitaxial growth of large-area single-layer graphene over $\mathrm{Cu}(111)$ /sapphire by atmospheric pressure CVD. Carbon 50, 57-65 (2012)
9. Orofeo, C.M., Hibino, H., Kawahara, K., Ogawa, Y., Tsuji, M., Ikeda, K., Mizuno, S., Ago, H.: Influence of $\mathrm{Cu}$ metal on the domain structure and carrier mobility in single-layer graphene. Carbon 50, 2189-2196 (2012)

10. Ma, L.P., et al.: Controllable growth of millimeter-size graphene domains on Cu foil. Chin. Sci. Bull 57, 2995-2999 (2012)

11. Regmi, M., Chisholm, M.F., Eres, G.: The effect of growth parameters on the intrinsic properties of large-area single layer graphene grown by chemical vapor deposition on $\mathrm{Cu}$. Carbon 50, 134-141 (2012)

12. Vlassiouk, I., Fulvio, P., Meyer, H., Lavrik, N., Dai, S., Datskos, P., Smirnov, S.: Large scale atmospheric pressure chemical vapor deposition of graphene. Carbon 54, 58-67 (2013)

13. Xu, Y., Wu, X., Ye, C.: Growth of graphene-like thin films at low temperature by dual-frequency capacitively coupled plasma. Appl. Surf. Sci 258, 7751-7754 (2012)

14. Vlassiouk, I., Regmi, M., Fulvio, P., Dai, S., Datskos, P., Eres, G., Smirnov, S.: Role of hydrogen in chemical vapor deposition growth of large single-crystal graphene. Acs Nano 5, 6069-6076 (2011)

15. Luo, Z., Lu, Y., Singer, D.W., Berck, M.E., Somers, L.A., Goldsmith, B.R., Charie Johnson, A.T.: Effect of substrate roughness and feedstock concentration on growth of wafer-scale graphene at atmospheric pressure. Chem. Mater 23, 1441-1447 (2011)

16. Campo, V., Henriquez, R., Haberle, P.: Effects of surface impurities on epitaxial graphene growth. Appl. Surf. Sci 264, 727-731 (2013)

17. Sharma, S., Klita, G., Hirano, R., Hayashi, Y., Tanemura, M.: Influence of gas composition on the formation of graphene domain synthesized from camphor. Material Lett 93, 258-262 (2013)

18. Batzill, M.: The surface science of graphene: metal interfaces, CVD synthesis, nanoribbons, chemical modifications and defect. Surf. Sci. Rep 67, 83-115 (2012)

19. Memon, N.K., Tse, S.D., Chhowalla, M., Kear, B.H.: Role of substrate, temperature, and hydrogen on the flame synthesis of graphene films. Proceeding of the combustion institute 34, 2163-2170 (2012)

20. Ferrari, A.C., Meyer, J.C., Scardaci, V., Casiraghi, C., Lazzeri, M., Mauri, F., Piscanec, S., Jiang, D., Novoselov, K.S., Roth, S., Geim, A.K.: Raman spectrum of graphene and graphene layers. Phys. Rev. Lett 97, 187401 (2006)

21. Ferrari, Andrea C.: Raman spectroscopy of graphene and graphite: disorder, electron-phonon coupling, doping and nonadiabatic effects. Solid State Commun 143, 47-57 (2007) 